\title{
LOSS OF NUCLEAR ACID DURING FERMENTATIVE TREATMENT OF HUMAN LYMPHOCYTES
}

\author{
YOICHIRO SASAI, KOJI KAWAMURA AND KAZUHIKO NAMBA \\ Department of Dermatology, Kurume University School of Medicine, \\ Kurume 830, Japan
}

Received for publication February 9, 1979

\begin{abstract}
The loss of DNA from human lymphocytes during trypsin or $\alpha$-chymotrypsin treatment was investigated with cytofluorometry. The decrease of fluorescence intensity was most remarkable with trypsin treatment, even when incubation was carried out at $4{ }^{\circ} \mathrm{C}$. In contrast, $\alpha$-chymotrypsin treatment had very little effects on the fluorescence intensity.
\end{abstract}

\section{INTRODUCTION}

There are some difficulties in the cytophotometric Feulgen-DNA measurement of epidermal cells using tissue sections. The main problem is caused by cut nuclei, resulting in erroneously low DNA values. As demonstrated by the calculations of Würthner et al. (1972), more than $50 \%$ of the nuclei are cut into sections of $10 \mu$ in thickness. This precludes exact determinations of the absolute DNA content of epidermal nuclei. Thus, it is necessary to separate and isolate intact nuclei of the epidermis. The action of different enzymes has been applied to dissociate the epidermis into its constituents.

However, it is a common disadvantage of all enzymatical methods to cause more or less decomposition of the nuclear acid to be measured (Tsanev and Markov, 1960 ; Filkuka et al., 1968 ; Franke et al, 1973). This study concerns with the loss of DNA during cytological preparation with enzymes.

\section{MATERIALS AND METHODS}

Human lymphocytes were collected from five healthy males with the method of Deitch et al. (1968). They were incubated in trypsin or $\alpha$-chymotrypsin solution at $4{ }^{\circ} \mathrm{C}$ or $37^{\circ} \mathrm{C}$ for prescribed periods. The final concentration of each enzyme in Hanks' balanced sterile saline solution was $0.1 \%, 0.25 \%$ or $0.5 \%$.

At the end of each incubation period, they were washed twice with physiological saline and smeared on glass slides. Then, they were fixed in $10 \%$ neutralbuffered formalin for 1 hour at room temperature and washed with distilled water before staining.

For the staining of DNA by the Feulgen method acid hydrolysis was performed in $5 \mathrm{~N}$ hydrochloric acid at $25^{\circ} \mathrm{C}$ for 40 minutes, followed by a 10 minute rinse in running water. Pararosaniline Schiff's reagent was diluted to $0.05 \%$ in glycine buffer adjusted to $\mathrm{pH}$ 2.3. The diluted Schiff's reagent was chilled beforehand to $10{ }^{\circ} \mathrm{C}$ in cold 
water bath and Schiff's reaction was carried out at this low temperature for 10 minutes. Then, the slides were transferred to bisulfite rinse which had been kept at $10^{\circ} \mathrm{C}$. After 3 changes of the bisulfite solution, the slides were washed thoroughly in running water for 1 hour, dehydrated with absolute ethanol and mounted with non-fluorescent embedding medium (Entellan, Merk). In order to stabilize the specific fluorescence, the slides were further postirradiated for 6 hours with the green light containing the excitation peak for pararosaniline Feulgen staining.
The instrument used for cytofluorometry was the microfluorometer Olympus MMSP-FR (Olympus Company, Tokyo, Japan). For excitation, green light through an interference filter AS540 together with a red-suppressing filter BG 38 was used. The barrier filter used was R610.

\section{RESULTS}

The results are summarized in Tables 1 and 2. Each figure is given as the mean of measurements on 1,000 cells, expressed as an arbitrary unit. The

TABLE 1

Effect of trypsin treatment on the Feulgen intensity of human lymphocytes*

\begin{tabular}{c|c|c|c|c|c|c}
\hline $\begin{array}{c}\text { Concentration } \\
\text { of Trypsin (\%) }\end{array}$ & $\begin{array}{c}\text { Temperature } \\
\left({ }^{\circ} \mathrm{C}\right)\end{array}$ & 0 & 30 & 60 & 90 & 120 \\
\hline 0.1 & 4 & $20.0 \pm 0.16$ & $19.9 \pm 0.43$ & $17.4 \pm 0.29$ & $16.2 \pm 0.28$ & $15.7 \pm 0.27$ \\
& 37 & & $16.3 \pm 0.26$ & $14.0 \pm 0.27$ & $12.6 \pm 0.25$ & $12.0 \pm 0.21$ \\
0.25 & 4 & & $19.8 \pm 0.38$ & $17.7 \pm 0.34$ & $16.4 \pm 0.33$ & $15.9 \pm 0.35$ \\
& 37 & & $15.1 \pm 0.32$ & $13.8 \pm 0.27$ & $11.9 \pm 0.22$ & $10.0 \pm 0.16$ \\
0.5 & 4 & & $19.1 \pm 0.24$ & $17.7 \pm 0.31$ & $13.3 \pm 0.23$ & $12.3 \pm 0.27$ \\
& 37 & & $17.0 \pm 0.34$ & $14.2 \pm 0.31$ & $14.1 \pm 0.27$ & $11.9 \pm 0.52$ \\
\hline
\end{tabular}

* Expressed as arbitrary units. Each figure represents the average of 1,000 determinants \pm standard deviation of the mean. Experimental procedures as described in the text.

TABLE 2

Effect of $\alpha$-chymotrypsin treatment on the Feulgen intensity of human lymphocytes*

\begin{tabular}{c|c|c|c|c|c|c}
\hline $\begin{array}{c}\text { Concentration } \\
\text { of } \alpha \text {-Chymo- } \\
\text { trypsin }(\%)\end{array}$ & $\begin{array}{c}\text { Temperature } \\
\left({ }^{\circ} \mathrm{C}\right)\end{array}$ & 0 & 30 & 60 & 90 & 120 \\
\hline \multirow{2}{*}{0.1} & 4 & $20.2 \pm 0.16$ & $19.7 \pm 0.31$ & $19.6 \pm 0.19$ & $18.7 \pm 0.29$ & $17.7 \pm 0.31$ \\
& 37 & & $19.8 \pm 0.27$ & $19.4 \pm 0.18$ & $18.2 \pm 0.32$ & $17.4 \pm 0.26$ \\
0.25 & 4 & & $19.9 \pm 0.22$ & $19.5 \pm 0.20$ & $18.4 \pm 0.15$ & $17.1 \pm 0.25$ \\
& 37 & & $19.8 \pm 0.26$ & $19.3 \pm 0.22$ & $18.0 \pm 0.27$ & $17.1 \pm 0.28$ \\
0.5 & 4 & & $19.2 \pm 0.35$ & $18.6 \pm 0.42$ & $17.7 \pm 0.21$ & $16.6 \pm 0.33$ \\
& 37 & & $18.0 \pm 0.25$ & $16.1 \pm 0.34$ & $16.0 \pm 0.17$ & $15.1 \pm 0.29$
\end{tabular}

* Expressed as arbitrary units. Each figurere represents the average of 1,000 determinants \pm standard deviation of the mean. Experimental procedures as described in the text. 
decrease of fluorescence intensity was most remarkable with trypsin treatment, even when incubation was carried out at $4^{\circ} \mathrm{C}$. In contrast, $\alpha$-chymotrypsin treatment had very little effects on the fluorescence intensity.

\section{DISCUSSION}

Beside the labelling index with radioactive thymidine the statistical distribution of DNA values is an important parameter of cell proliferation. For most purposes the knowledge of the relative amount of DNA is sufficient. The dissociation of the tissues into single cells is a basic requirement for any cytophotometric determination of cellular DNA-content, since the measurements of tissue sections cause erroneously low values (Würthner et al, 1972). For the dissociation of tissues many methods have been reported. Most of them consist in a combination of mechanical homogenization and enzymatic treatment to gain a suspension of single cells. This procedure is successful with trypsin or $\alpha$-chymotrypsin.

For the quantitative determination of nuclear acids a factor of uncertainty is involved with the enzymatic isolation of single cells, resulting from losses during preparation. And, the losses as a function of incubation time do not follow simple laws. Cowden (1957) considered the lack of purity of the enzymes as a source of losses. Franke et al. (1973) emphasized the uncertainty of quantitative evaluation on the losses of material during cytological preparation of nuclei. Tsanev and Markov (1960) observed that biochemical determination showed the epidermis of mouse separated by trypsin $\left(0.5 \%, 37^{\circ} \mathrm{C}, 1\right.$ hour) to have a DNA loss of $43 \%$. Filkuka et al. (1968), who combined hyaluronidase, elastase and trypsin to separate the epidermis of hairless mouse, noticed a $5 \%$ decrease in the Feulgen stainability with absorption cytophotometry. In the absorption cytophotometry they used, however, the correction is required for residual distribution error and glare.

With cytofluorometry, Alavaikko (1971) found that the fluorescence intensity of the basal cells in mouse epidermis decreases strikingly at a 2hour incubation in a $0.25 \%$ trypsin solution at $37^{\circ} \mathrm{C}$. $\alpha$-Chymotrypsin incubation retained the fluorescence intensity unchanged up to 2.5 hours. On the other hand, the present study indicated that the decline in the fluorescence intensity of human lymphocytes is found after 30 minutes of incubation in a $0.1 \%$ trypsin solution at $37^{\circ} \mathrm{C}$. The effect of $\alpha$-chymotrypsin $(0.25 \%$, $37^{\circ} \mathrm{C}$ ) was negligible up to 60 minutes. Using fluorescence the excited molecules are light source of their own and the total amount of light quanta emitted from the fluorescent structure is equally measured by a photocell, no matter whether these structures are evenly or irregularly distributed within the measuring field. Thus, the distributional errors inherent in absorption cytophotometry are avoided with cytofluorometry. However, there are some important problems such as fluorescence fading and partial non-linearity between fluorescence intensity and concentration of fluorescent substance. Böhm and Sprenger (1968), and Prenna et al. (1974) asserted that a linear relationship does exist between the content of Feulgen-DNA and the intensity of the fluorescent light unless the concentration of the Feulgen dyes exceeds a certain limit. Fujita and his coworkers (Fujita, 1973; Fujita and Fukuda, 1974; Fukuda et al., 1977) pointed out that heavy staining with Feulgen dyes definitely destroys the proportionality between the Feulgen- 
DNA content and the total amount of fluorescence of the nucleus, and found the destruction of the primary fluorescence in the back ground with stabilization of specific fluorescence of pararosaniline by irradiation of specimen with the strong excitation light.

According to them, proportionality between the amount of fluorescence and DNA content is perfectly preserved and the standard deviation in each class of ploidy became less than $5 \%$ of the mean DNA value. In the present study, we used pararosaniline as a Feulgen dye, while Alavaikko (1971) employed BAO. The difference between Alavaikko's data and ours may be based on the difference of dye used.

According to our preliminary study (Sasai et al., unpublished data), epidermal cells were well separated from each other after the incubation in a $0.25 \%$ $\alpha$-chymotrypsin solution for 45 minutes at $37^{\circ} \mathrm{C}$. Thus, it may be concluded that $\alpha$-chymotrypsin is a useful agent to obtain a pure suspension of epidermal cells.

\section{ACKNOWLEDGEMENTS}

This study was partially supported by Grant-in-Aid for Scientific Research from the Ministry of Education, Science and Culture of Japan (No. 248233).

\section{REFERENCES}

Alavaikko, M. (1971). Selective separation of mouse epidermal epidermal cells and cytophotometric estimation of their nuclear DNA. Acta Path. Micr. Scand, Suppl. 226.
BöHm, N. and SPREnger, E. (1968). Fluorescence cytophotometry: A valuable method for the quantitative determination of nuclear Feulgen-DNA. Histochemie, 16, 100-118.

Cowden, R. R. (1957). Methods for the study of the cytochemistry of nucleic acids and chromosomes. Mikroskopie, 12, 11-21.

Deitch, A.D., Wagner, D. and Richart, R.M. (1968). Conditions influencing the intensity of the Feulgen reaction. J. Histochem. Cytochem., 16, 371-379.

Filkuka, J., Lederer, B. and SANDritter, W. (1968). Loss of basic nuclear protein during fermentative isolation of epidermal cells. Acta Histochem., 29, 263-269.

Franke, W. W., Deumlung, B. and Zentgraf, H. (1973). Losses of material during cytological preparation of nuclei and chromosomes. Exp. Cell Res., 80, 445-449.

Fujita, S. (1973). DNA cytofluorometry on large and small cell nuclei stained with pararosaniline Feulgen. Histochemie, 36, 193-199.

Fujita, S. and Fukuda, M. (1974). Irradiation of specimens by excitation light before and after staining with pararosaniline Feulgen : A new method to reduce non-specific fluorescence in cytofluorometry. Histochemistry, 40, 59-67.

Fukuda, M., Nakanishi, K., Sawamura, I. and Fujita, S. (1977). Standardization of the post-irradiation method to eliminate primary fluorescence in cytofluorometry. Histochemistry, 52, 119-127.

Prenna, G., Levia, S. and Mazzini, G. (1974). Quantitation of DNA by cytophotometry of the conventional Feulgen reaction. Histochem. J., 6, 467-489.

TSANEv, R. G. and Markov, G. G. (1960). Nucleic acid content in mouse epidermis separated from dermis by different method. Experimentia, 16, 448.

WÜrthner, K, SAcks, H. and Bahnsen, J. (1972). Zum Problem der Kernanschnitte bei der Zytophotometrie an histologischen Präparaten. Histochemie, 32, 261-270. 